\title{
Personality traits, anger and psychiatric symptoms related to quality of life in patients with newly diagnosed digestive system cancer
}

\author{
Noemi Peres HONORAT01,2, Luciene Vaccaro de Morais ABUMUSSE ${ }^{3}$, \\ Daniel Pereira COQUEIRO ${ }^{2}$ and Vanessa de Albuquerque CITERO $^{3}$
}

Received 19/7/2016

Accepted 29/11/2016

\begin{abstract}
Background - The presence of psychiatric symptoms, anger, and personality characteristics are factors that affect the quality of life of newly diagnosed digestive system cancer patients. Objective - This study aims to identify which stable characteristics of the individual's personality interfere with quality of life, even when reactive emotional characteristics of falling ill are controlled. Methods-A cross-sectional study was performed at the Oncology Clinic (Hospital das Clinicas), Marília/SP, Brazil, in which 50 adult patients with digestive system cancer and diagnosed less than 6 months answered the State-Trait Anger Expression Inventory, Temperament and Character Inventory, Hospital Anxiety and Depression Scale and WHOQOL-BREF. Multiple regression was performed to verify if quality of life was related to stable characteristics of the subject's personality (anger trait, temperament and character) after controlling to the transient emotional aspects (anger state, psychiatric symptoms). Results - The quality of life psychological health score was higher in presence of self-directedness character and reward dependence temperament and quality of life environment score was higher in presence of self-directedness character and lower in presence of harm avoidance temperament. Conclusion - The psychological well-being and the adaptive needs to the environment that favoring a better quality of life were reinforced mainly by the self-directedness character; which means that patients more autonomous cope better with the disease. On the other hand, the harm avoidance temperament (meaning the patient has fear of aversive situations) impaired the adaptive capacity to deal with the changes of the day-to-day imposed by the disease. Understanding these personality traits is important to the health professionals drive the patient to more successful treatment.
\end{abstract}

HEADINGS - Digestive system neoplasms. Personality. Anxiety. Depression. Quality of life.

\section{INTRODUCTION}

It is known that cancer is the second cause of death in the world ${ }^{(39)}$ being the colorectal neoplasm the third kind of cancer in men and the second in women ${ }^{(38)}$. Due to this high prevalence of the disease is important to comprehend the psychological aspect of the disease.

The prognosis and treatment response that a cancer patient has suffers direct interference of psychosocial aspects ${ }^{(3,35)}$, and environmental conditions ${ }^{(14)}$.

From the point of view of quality of life (QOL), it is noted that the oncologic patient suffers from some changes that can generate a dependence on their formal and informal caregivers, harming the physical, psychological, social and spiritual aspects of the newly diagnosed individual ${ }^{(17)}$.Thus, patients with cancer of the oral cavity, oropharynx, hypopharynx and larynx have a high prevalence of depressive symptoms and low functional and psychological level at the beginning of treatment, which may be predictors of increased severity of symptoms and malfunction of these post-treatment states ${ }^{(22)}$. Patients with gastrointestinal cancer show a decrease in QOL due to the presence of anguish, anxiety and depression symptoms ${ }^{(41,42)}$ and those with laryngeal cancer and who underwent total or partial laryngectomy also present a deficit in social and emotional functions in QOL scores ${ }^{(9)}$ and in people with gastric cancer, hopelessness is observed as a major impact on QOL ${ }^{(34)}$.

In fact, emotional reactions to cancer are important aspects in understanding the patient's QOL. A study ${ }^{(31)}$ with 68 newly diagnosed head and neck cancer patients were consecutively selected to declare their perceptions about the disease and the own quality of life; it was concluded that the more concerned the patient was with the physical symptoms the more intense was the emotional reactions related to the disease, and the lower was the QOL scores. Other study ${ }^{(12)}$ with 180 hepatic and colon cancer patients that answered about stressors aspects, coping and QOL related to the disease showed that patients with more active personality and more resilient had higher psychologic well-being and QOL.

Being passive and active attitudes as coping strategies, it is important to identify which feelings are evolved in QOL aspects, mainly in newly diagnosed patients. It is known that the impact of the diagnosis of cancer can cause damage to anger control, with the expression of negative affect ${ }^{(37)}$, and that $12 \%$ of gastric cancer subjects showed anger at facing the disease situation ${ }^{(33)}$. Another factor with little scientific information regards to the influence

${ }^{1}$ Faculdade de Medicina de Marília (FAMEMA), Marília, SP, Brasil; ${ }^{2}$ Faculdade de Ensino Superior do Interior Paulista (FAIP). Marília, SP, Brasil; ${ }^{3}$ Escola Paulista de Medicina, Universidade Federal de São Paulo (UNIFESP), SP, Brasil.

Correspondence: Noemi Peres Honorato. Faculdade de Medicina de Marília (Famema). Av. Monte Carmelo, 800. CEP: 17519-030 - Bairro Fragata - Marília, SP. Brasil. E-mail: noemiperes@ hotmail.com 
that personality characteristics of the subject and its cognitive and behavioral form of conflict situations coping act for a psychological adjustment of the individual. The personality traits of patients with gastric cancer can interfere with $\mathrm{QOL}^{(40)}$; it is observed that personality type $\mathrm{D}$, which is characterized by traits of negative affectivity and social inhibition, was also investigated in patients with colorectal cancer showing that this type of personality interferes negatively on the QOL ${ }^{(32)}$. Along the same lines, temperament characteristics and character have not demonstrated clearly interfering factors in anxiety and depression ${ }^{(6)}$.

Clinically, these factors are not presented in a fragmented way, i.e., feelings, emotions and personality of the newly diagnosed cancer patient form one single set in the patient. The importance of understanding how these factors work together in newly diagnosed patients with digestive system cancer is to develop more information that may sustain better psychological treatment to these patients. This study aims to identify which stable characteristics of the subject's personality (trace of anger, temperament and behavior), therefore the most difficult aspects to be modified interfere in various fields of quality of life, controlling the transitional emotional characteristics reactive to the disease (state of anger, depressive and anxious symptoms) that interfere with the expression of the patient's personality.

\section{METHODS}

This is a survey study developed between July of 2011 and November of 2012 at the Oncology Clinic, a multiprofessional facility from the Hospital das Clinicas of the Faculdade de Medicina de Marília (FAMEMA), in Marilia - Sao Paulo, Brazil. The hospital attends the Marilia region that comprises 62 nearby cities being the reference to patients with high complexity diseases as cancer.

The sample size was estimated to have at least 40 patients, to guarantee 10 patients ( $25 \%$ of the included patients) ${ }^{(29)}$ with minor psychiatric symptoms. It would improve the statistical analysis quality. They were selected by convenience, including all patients that comprise the inclusion criteria: have digestive cancer diagnosed for less than 6 months and over 18 years old. The exclusion criteria were the patients have a mini-mental score below of the minimum to the own educational level to avoid patients with cognitive impairment ${ }^{(10)}$, as well as the ones who did severe clinical conditions to respond to the questionnaires (either hospitalized or in home care). From a population of 792 patients listed in the facility with digestive cancer, 120 were included in the study but 10 had severe clinical conditions to respond to the questionnaires being excluded. Thus, all the 110 eligible patients from the study sample were equally invited to participate during their scheduled visit to the clinic. Sixty patients $(50 \%)$ answered a part of the study protocol but then refused to continue alleging it was too much difficult (17 patients) or too long enough (43 patients). Only 50 patients completed the protocol (Figure 1).

Two psychologists were trained to apply the instruments; to not explain the questionnaires in order to avoid bias of answers, and to read the questions to the patients in case they have difficulty. The patients were approached by them before consultation or medical procedure for which had already been scheduled. After filling out the Informed Consent, they answered the mini-exam of the mental state $^{(10)}$ and a questionnaire to identify the sociodemographic and clinical characteristics and the instruments already validated for use in Brazil:
1. Hospital Anxiety and Depression Scale-HADS ${ }^{(7)}$ was applied to identify symptoms of anxiety and depression. There are two subscales, one about anxiety symptoms (diagnostic sensitivity of $93.7 \%$ and specificity of $72.6 \%$ ) and other about depressive symptoms (diagnostic sensitivity of $84.6 \%$ and specificity of $90.3 \%$ ), each ranging from 0 to 21 , wherein the higher the score, the greater the presence of symptoms; and the cut $8 / 9$ represents the absence or presence of symptoms, respectively.

2. State-Trait Anger Expression Inventory-STAXI ${ }^{(5)}$ was applied to identify trait components, state and direction of anger. There are six subscales that comprise: a personality trait domain of chronic anger, an anger state domain related to the current situation, and four domains on the direction of anger (which are not used in this study).The results of the chronic anger trait domain and rage state domain are expressed in scores and categorized according to percentiles, where scores below 25 represents that the subject uses excessive denial defenses and repression of feelings of anger, many times unacceptable; percentiles between 25 and 75 indicates that the score is in the range considered normal for these elements; and score above 75 indicates that the subject is very inclined to experience or express feelings of anger to a degree that may interfere with interpersonal relationships, leading him to predispose to develop physical and mental disorders.

3. Temperament and Character Inventory - TCI ${ }^{(20,25)}$ was applied to describe personality characteristics through four temperament factors (novelty seeking - the behavior in response to new stimuli; harm avoidance - the inhibition of behavior in response

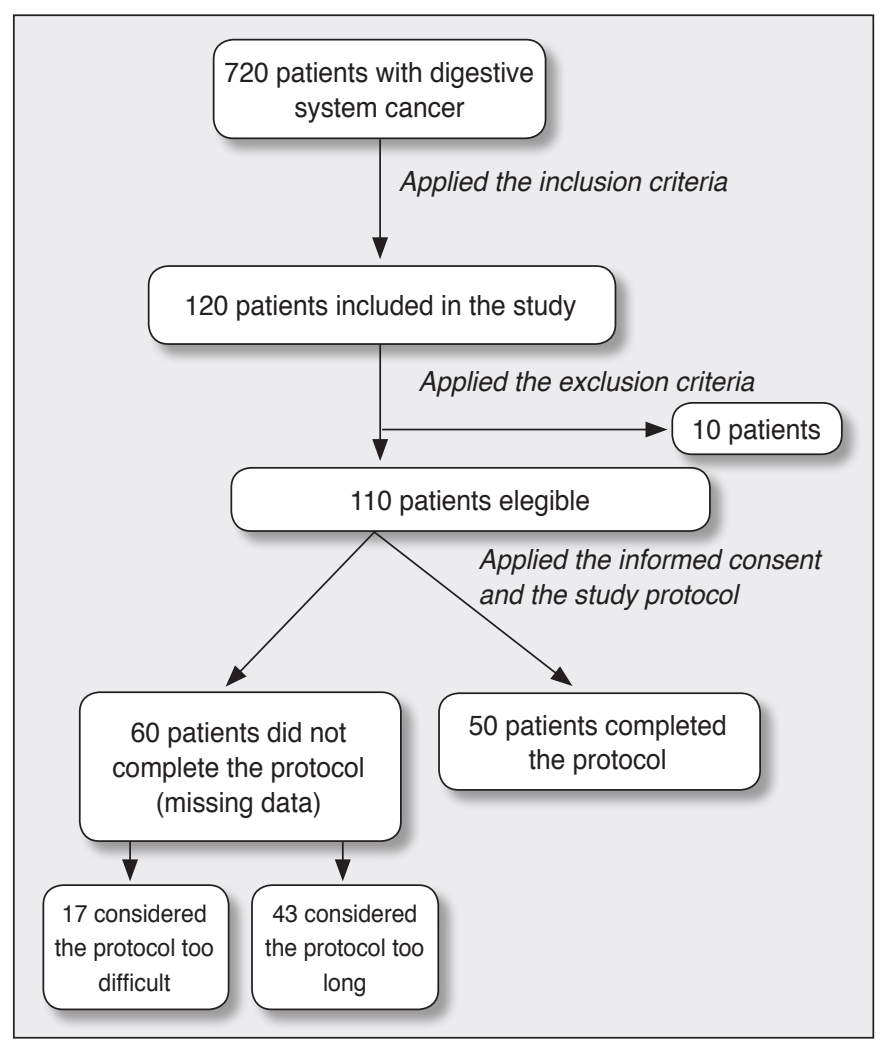

FIGURE 1. Sample description 
to punishment; reward dependence - the need for rewards, and persistence - the ability to maintain behavior despite frustration or fatigue) and three of character (self-directedness - the autonomy of subject, defining his characteristics of responsibility, confidence and direction in relation to a goal; cooperativeness - the conception of the subject in relation to society, to other, and self- transcendence - the system of the individual's ideals in relation to the universe and to God). The confiability of the Brazilian version were satisfatory (alpha- Cronbach of 0.74 to novelty seeking, 0.81 to harm avoidance, 0,71 to reward dependency, 0.43 to persistence, 0.90 to self-directeness, 0.80 to cooperativeness, and 0.92 to self -transcendence) ${ }^{(20,25)}$. As in STAXI, the result is expressed in scores and categorized according to percentile; the lower or higher the score of each factor, the less or more representative Will be the presence of this factor, without flexibility, showing inadequacy in the modulation of the subject before the presented reality.

4. WHOQOL-Bref ${ }^{(19)}$ that assesses the quality of life related to health in 4 domains: physical (how the subject deals with pain, energy, sleep, mobility, activities of daily living, dependence on medication/treatment and capacity to work), psychological (how the subject deals with positive and negative feelings, ability to think and learn, self-esteem and body image, and spirituality), social relationships (how the subject deals with personal relationships, social support and sexual activity) and environment (how the subject deals with their physical safety, home environment, financial resources, leisure and transport). Each domain has a result expressed in percentage: the higher the percentage, the better quality of life in that domain.

A descriptive analysis was performed through the calculation of absolute and relative frequencies of the variables, in addition to measures of central tendency (mean, median) and dispersion (standard deviation). To assess the relationship between the stable variables of personality (trace of anger, temperament and behavior), transient emotional states (state of anger, depressive and anxious symptoms) and domains of quality of life, we used Spearman correlation test, considering measures from 0.4 as strong correlation coefficient ${ }^{(1)}$

Finally, four multiple hierarchical regression method enter were performed to verify if each outcome variable (QOL domains: physical, psychological, environment and social relationship) was stable characteristics of the subject's personality (anger, temperament and character) after controlling to the transient emotional aspects (state of anger, depression and anxiety symptoms). To avoid spurious results, each model of regression had the independent and control variables defined by the statistical significant results of the Spearman correlation.

The significance level used in the analyzes was $P<0.05$ and the analysis was performed using Statistical Package for Social Sciences (SPSS) version 20.0. The study was approved by the ethics and research committees of FAMEMA (protocol 465/11) and Universidade Federal de São Paulo - UNIFESP (Protocol 1580/11).

\section{RESULTS}

\section{Description of the sample and psychosocial variables}

The patients were, on average, 56 \pm 11 years (33-74 years range); in a 16 to 180 days variation, cancer diagnosis time had an average of $114 \pm 46$ days. Other clinical and demographics characteristics of newly diagnosed patients with digestive tract cancer are described in Table 1.

TABLE1. Clinical and demographics characteristics of newly diagnosed patients with digestive system cancer

\begin{tabular}{lc}
\hline Characteristics & N (\%) \\
\hline Gender: male & $33(66.0)$ \\
Live with a partner & $38(76.0)$ \\
Scholarship level: up to elementary school & $21(42.0)$ \\
Work situation: patient is retired or have a medical license & $27(54.0)$ \\
Infradiaphragmatic portion of the tumor in digestive tract & $34(68.0)$ \\
Stage degree of the tumor III or IV & $38(76.0)$ \\
Presence of comorbidities as hypertension and diabetes & $14(28.0)$ \\
Use of psychoactive substances (alcohol and tobacco) & $9(18.0)$ \\
$\begin{array}{l}\text { Use of psychiatric medication (antidepressives and } \\
\text { ansyolitics) }\end{array}$ & $10(20.0)$ \\
\hline
\end{tabular}

Table 2 showed the central tendency of the stable and transitional emotional characteristics of subjects' personality and the quality of life.

TABLE 2. Stable and transitional emotional characteristics of personality of newly diagnosed patients with digestive system cancer

\begin{tabular}{lcc}
\hline & Median & Range \\
\hline Stable characteristics of personality & & \\
Chronic anger trait & 17.0 & $10.0-40.0$ \\
Novelty seeking temperament & 14.5 & $6.0-26.0$ \\
Harm avoidance temperament & 15.0 & $4.0-26.0$ \\
Reward dependence temperament & 13.0 & $4.0-23.0$ \\
Persistence temperament & 5.0 & $1.0-8.0$ \\
Cooperativeness character & 33.0 & $12.0-41.0$ \\
Self-transcendence character & 21.5 & $7.0-32.0$ \\
Self-directedness character & 32.0 & $14.0-44.0$ \\
Transient characteristics related to falling ill & & \\
Anger state & 10.0 & $10.0-29.0$ \\
Anxious symptoms & 4.00 & $0-15$ \\
Depressive symptoms & 0 & $0-16$ \\
Quality of life domains & & \\
Physical health & $61 \%$ & $21 \%-79 \%$ \\
Psychological health & $63 \%$ & $17 \%-79 \%$ \\
Social relationships & $67 \%$ & $17 \%-92 \%$ \\
Environment & $69 \%$ & $34 \%-100 \%$ \\
\hline
\end{tabular}

\section{Assessment of stable personality characteristics and transient emotional states related to falling ill}

Table 3 shows the study of correlation between QOL domains and the personality characteristics and transient states of patients with newly diagnosed digestive system cancer. Although several correlations have shown to be statistically significant, the coefficient found showed a higher correlation than or equal to 0.40 only for some aspects related to psychological health and the environment. The patient's psychological health was correlated with two characteristics of stable personality traits, reward dependence tempera- 
TABLE 3. Spearman's correlation coefficients between domains of quality of life and variables of anger, temperament and character, anxious and depressive symptoms

\begin{tabular}{|c|c|c|c|c|}
\hline & \multicolumn{4}{|c|}{ Quality of life } \\
\hline \multicolumn{5}{|l|}{ Stable characteristics of personality } \\
\hline Chronic anger trait & 0.01 & -0.26 & -0.26 & $-0.33 *$ \\
\hline Novelty seeking temperament & 0.07 & 0.12 & -0.04 & -0.05 \\
\hline Harm avoidance temperament & -0.22 & $-0.37 * *$ & -0.21 & $-0.44 * *$ \\
\hline Persistence temperament & $0.28 *$ & 0.16 & 0.12 & 0.24 \\
\hline Cooperativeness character & 0.04 & $0.33 *$ & $0.35 *$ & $0.33 *$ \\
\hline Self-transcendence character & 0.06 & 0.02 & 0.22 & 0.05 \\
\hline Self-directedness character & 0.13 & $0.43 * *$ & 0.23 & $0.45 * *$ \\
\hline Depressive symptoms & $-0.32 *$ & $-0.38 * *$ & -0.25 & $-0.29 *$ \\
\hline
\end{tabular}

$* P<0.05 ; * * P<0.01$

ment and self-directedness character $(\mathrm{r}=0.51$ and 0.43 respectively; $P<0.01)$. QOL due to environment domain was correlated with two stable characteristics, harm avoidance temperament and selfdirectedness character $(\mathrm{r}=-0.44$ and 0.45 respectively, $P<0.01)$ and a transient characteristic and emerged from falling ill, the state of anger $(\mathrm{r}=-0.40, P<0.01)$. The presence of depressive symptoms correlated with almost all domains (except social relationships), although with coefficients lower than 0.4.

In order to assess which personality factors impact on QOL, according to the results already shown in Table 3 , it was decided to build three blocks of linear regression models to explain QOL, one block with respect to psychological health and two blocks in relation to the environment. The depressive symptoms score was the control variable for QOL in both domains, and the environment was also controlled by the score state of anger in response to falling ill. Table 4 shows the results.
1. Both self-directedness character and reward dependence temperament are associated to quality of life related to psychological health of patients with newly diagnosed cancer of the digestive system, even after the control for depressive symptoms score, i.e., regardless of the patient presenting depressive symptoms or not, patients with higher score of self-directedness character had $42.2 \%$ more psychological health than patients with lower score. The same occurred to reward dependence (patients with higher score of reward recompense temperament had $32.3 \%$ more psychological health than patients with lower score). The variability of psychological health controlled by depression was correlated by self-directedness by $38 \%$ and by reward dependence by $31 \%$.

2. Both self-directedness character and harm avoidance temperament are associated to the quality of life related to the environ-

TABLE 4. Predictive study of personality factors on the quality of life related to psychological health and environment, controlled for the presence of depressive symptoms and anger state

\begin{tabular}{|c|c|c|c|c|c|}
\hline & \multirow{2}{*}{$\begin{array}{l}\text { Independent } \\
\text { variable }\end{array}$} & \multicolumn{2}{|c|}{ Standardized coefficients } & \multicolumn{2}{|c|}{$95.0 \%$ CI for beta } \\
\hline & & Beta & Sig. & Lower bound & Upper bound \\
\hline Control variable: depressive symptoms & RD score & .323 & .010 & .267 & 1.890 \\
\hline Control variable: depressive symptoms & HA score & -.324 & .018 & -1.436 & -.142 \\
\hline Dependent variable: environment & SD score & .415 & .005 & .244 & 1.301 \\
\hline Control variable: reactive anger state & HA score & -.389 & .010 & -1.660 & -.233 \\
\hline
\end{tabular}

SD: self-directedness; RD: reward dependence; HA: harm avoidance. 
ment of the newly diagnosed patient, even after the control for the depressive symptoms score, i.e., regardless of the patient present depressive symptoms or not, patients with higher score of self-directedness had $34.9 \%$ more quality of life related to the environment than patients with lower score. The opposite occurred to harm avoidance: patients with higher score of harm avoidance had $32.4 \%$ less quality of life related to the environment than patients with lower score. The variability of the environment controlled by depression was related to selfdirectedness by $21 \%$ and harm avoidance by $20 \%$.

3. Both self-directedness character as harm avoidance temperament are associated to quality of life related to the environment of the newly diagnosed patient, even after controlling for state of anger score in response to falling ill, i.e., regardless of the patient to be angry or not, patients with higher score of self-directedness had $41.2 \%$ more quality of life related to the environment than patients with lower score. The opposite occurred to harm avoidance: patients with higher score of harm avoidance had $38.9 \%$ less quality of life related to the environment than patients with lower score. The variability of environment controlled by anger was related to self-directedness by $14 \%$ and by harm avoidance by $12 \%$.

\section{DISCUSSION}

Patients diagnosed with cancer of the digestive system for less than 6 months showed personality traits that favored, and others that have harmed their quality of life, regardless of the emotions triggered by falling ill. Besides the impact that personality aspects have on the psychological health of the patient, it was realized that the quality of life related to environment was one aspect that emerged as susceptible at the time of the disease.

Environment has been an important aspect in quality of life of cancer patients in spite of the length of the disease. Comparing 309 colorectal cancer patients in Germany with 15 months of diagnostic and general population at same demographic characteristics, Arndt et al. ${ }^{(2)}$ identified a similar quality of life between groups but financial aspects were more impaired with the disease. The environment quality of life domain relates to how the subject deals with their physical safety, home environment, financial resources, leisure and transportation ${ }^{(19)}$; it is then learned that this domain explores the impact that a critical situation in life has on the day-to-day life of the individual and his need to have access to medical treatment. In the first six months of a serious disease, the impact of the disease affects the individual in many ways, but even considering patients in more advanced stages of digestive system cancer, the need for reorganization his daily life is reflected in the change of the environment.

People with a predominance of self-directedness character, that is, with autonomy and greater appropriation of their responsibilities, with confidence and able to drive toward a goal (treatment), felt with more quality of life to deal with new routine. It is important to note that this capability was not impaired by feelings of depression or anger at the disease. The self-directedness character was also a determining factor for the psychological health of the patient, i.e., feeling autonomous helped the patient to deal with their positive and negative feelings, and felt self-esteem, regardless of the presence of depressive symptoms. These feelings related to self-esteem can be found as characteristics of personality ${ }^{(27)}$. Besides feelings, other aspects can be affected by cancer, as the social field of interpersonal relationships (spouses, family, friends), labor and productive life ${ }^{(2,15)}$. Experiencing the process of being ill with cancer may lead to consequences or even interrupt the routine, directly impacting their quality of life.

Quality of life related to the environment was impaired in patients with harm avoidance temperament, i.e., patients that inhibit certain behaviors after feeling punished by something or someone, independent of depressive symptoms or anger in the face of the disease. These patients show signs of negative feelings, insecurity and fear of threatening and aversive situations ${ }^{(13)}$. Thus, when experiencing the disease and treatment, this type of patient attempts to distance himself from the problem, and tends to minimize symptoms for a longer period of time than others ${ }^{(13)}$.

Another aspect found in our study was the state of anger present at the moment of treating the disease, which showed relatively low score. Jukulsen et al. ${ }^{(23)}$ studied the role of anger in 153 patients with cancer in the first 8 months of diagnostic, prospectively. They showed that low scores of anger is normal but more important is the quality of anger that the patient expresses; which means, anger expression and anger control are positive to improve quality of life, and anger inhibition decreases it. Other study with 637 colorectal cancer patients showed that denial or repression of anger in patient's life story is a mark to this kind of cancer ${ }^{(24)}$.

From a clinical point of view, even with low score of anger state, the objective of studying was attended: the role of stable characteristics personality in these patients is relevant to some aspects of the quality of life of the newly diagnosed patient with digestive tract cancer. This is a problem because these characteristics are more difficult to be modified. The health professional who attend these patients need to understand their difficulty to deal with the diagnostic. Chao ${ }^{(11)}$ suggests more attention to the psychosocial needs of patients at the beginning of the adaptation process in order to strengthen them and support them emotionally for the return of their daily activities more quickly. It is understood that, as it is a chronic disease, patients need to live with their clinical situation according to their emotional possibilities ${ }^{(4)}$. Staying autonomous can foster greater involvement and responsibility with their health during treatment in this new life stage ${ }^{(36)}$. Due to the impairment caused by the disease and its stigma, it is still observed that this can mean deprivation of everyday sociability, segregation, and disruption of daily, occupational activities, and the absence from work. Thus, the access to goods and services are made more difficult ${ }^{(28,30)}$. During and after treatment, it is noteworthy, there may be possible loss of muscle mass causing functional impairment to the patient ${ }^{(16)}$.

Furthermore, treatment with chemotherapy, surgery and radiation therapy cause loss of strength and damage to normal tissues, and therefore there may be a loss of autonomy ${ }^{(8,26)}$. These changes bring psychological distress and the change in daily activities may be slowed with certain actions by the family and multidisciplinary team who serves them. This patient can benefit when he realizes that social support and emotional and physical support can help him change his habits improving his health ${ }^{(13,18)}$. This type of care interferes positively in coping mechanisms, which provides autonomy by clarifying and promoting his quality of life according to his living conditions ${ }^{(21)}$.

Some limitations of the study must be considered. Although the sample size was adequate to our purpose, it was collected by convenience and not randomically. Fifty-five percent of the eligible patients refused to participate in the study and it was no possible 
to control the missing data. The instruments together were too long to these patients what was the main reason to they decline to participate in the study. Other point to be considered is the low symptomology of depression and presence of anger state, what can be explained by three reasons: in fact a low presence of symptoms; the use of antidepressants what could minimize the symptoms; or a failure to collect data from who was more depressive or anger. Finally, the cross-sectional design does not allow more comprehension about the impact of the diagnostic on QOL (in the future more data will be present; this paper is a preliminary report of a longitudinal study with these patients)."

\section{CONCLUSION}

In this study there was a predominance of male patients with digestive tract cancer in infradiaphragmatic portion; they had diagnostic time of 4 months; presented factors as reward dependence and self-directedness character that favoring a better quality of life related to psychological health. This psychological well-being was reinforced by the self-directedness character; which means that patients more autonomous cope better with the disease. The adaptive needs to the environment that favoring a better QOL were also reinforced by the self-directedness character. On the other hand, the harm avoidance temperament (meaning the patient has fear of aversive situations) impaired the adaptive capacity to deal with the changes of the day-to-day imposed by the disease. Understanding these personality traits is important to the health professionals drive the patient to more successful treatment using strategies that help the patient to adhere well to the treatment.

\section{Authors' contributions}

Honorato NP: developed the research design, collected data and wrote the paper. Abumusse LVM: participated in discussion section. Coqueiro DP: participated in discussion section, statistical analysis, table elaboration. Citero VA: developed the research design and wrote the paper, statistical analysis, table elaboration.

Honorato NP, Abumusse LVM, Coqueiro DP, Citero VA. Traços de personalidade, raiva e sintomas psiquiátricos relacionados à qualidade de vida em pacientes com câncer do sistema digestório recém-diagnosticado. Arq Gastroenterol. 2017;54(2):156-62.

RESUMO - Contexto - A presença de sintomas psiquiátricos, raiva, e características de personalidade são fatores que interferem na qualidade de vida do paciente com câncer do sistema digestório recém-diagnosticado. Objetivo - Este estudo objetiva identificar que características estáveis da personalidade interferem na qualidade de vida, mesmo quando controladas as características emocionais reativas ao adoecer. Métodos - Um estudo transversal foi realizado na Clínica de Oncologia (Hospital das Clínicas), Marília/SP Brasil, no qual foram avaliados 50 pacientes adultos com câncer digestivo diagnosticados há menos de 6 meses que responderam ao Inventário de Expressão de Raiva Traço-Estado, Inventário de Temperamento e Caráter, Escala Hospitalar de Ansiedade e Depressão e WHOQOL-BREF. Regressão múltipla foi aplicada para verificar se a qualidade de vida estava relacionada com as características estáveis de personalidade (traço de raiva, temperamento, caráter) após controlar os resultados para a presença de aspectos emocionais transitórios (estado de raiva, sintomas psiquiátricos). Resultados - O escore de saúde psicológica da qualidade de vida foi maior na presença de caráter de autodirecionamento e do temperamento de dependência de gratificação; o escore de meio-ambiente da qualidade de vida foi maior na presença de caráter de autodirecionamento, e menor na presença de temperamento de evitação ao dano. Conclusão - $\mathrm{O}$ bem-estar psicológico e as necessidades adaptativas ao meio-ambiente que favorecem uma melhor qualidade de vida foram reforçados principalmente pelo caráter de autodirecionamento. Por outro lado, o temperamento de evitação ao dano prejudica a capacidade adaptativa de lidar com as mudanças diárias, impostas pela doença. Compreender estes traços de personalidade é importante para que os profissionais de saúde conduzam o paciente por um tratamento de maior sucesso.

DESCRITORES - Neoplasias do sistema digestório. Personalidade. Ansiedade. Depressão. Qualidade de vida.

\section{REFERENCES}

1. Altman DG. Practical statistics for medical research. Ed. Chapman \& Hall/CRC. London, 1991, pg. 295.

2. Arndt V, Merx H, Stegmaier C, Ziegler H, Brenner H. Quality of life in patients with colorectal cancer 1 year after diagnosis compared with the general population: a population-based study. J Clin Oncol. 2004;22:4829-36.

3. Bausewein C. [Thinking from the end - Does the diagnosis "cancer" make a difference to patients and carers?]. Z Evid Fortbild Qual Gesundhwes. 2013;107:136-9.

4. Bertan FC, Castro EK. [Quality of life, anxiety and depressions indicators and sexual satisfaction in adult patients with cancer]. Rev Salud Soc. 2010;1:76-88.

5. Biaggio AMB. Ansiedade, raiva e depressão na concepção de C. D. Spielberger [Anxiety, Angerand Depression According to the Concept of C.D. Spielberger]. Ver Psiquiatr Clín. 1999;25:291-3.

6. Bonacchi A, Miccinesi G, Guazzini M, Rossi A, Bacci S, Toccafondi A, et al. Temperament and character traits associated with health-related quality of life in cancer patients. Tumori. 2012;98:377-84.

7. Botega NJ, Bio MR, Zomignani MA, Garcia Jr C, Pereira WA. [Mood disorders among medical in-patients: a validation study of the hospital anxiety and depression scale (HAD)]. Rev Saúde Pública. 1995;29:355-63.

8. Bovio G, Bettaglio R, Bonetti G, Miotti D, Verni P. [Autonomy of the elderly patient with cancer: the right to know the diagnosis]. Acta Paul Enferm. 2007;20:509-13.
9. Braz DS, Ribas MM, Dedivitis RA, Nishimoto IN, Barros APB. Quality of life and depression in patients undergoing total and partial laryngectomy. Clinics (Sao Paulo). 2005;60:135-42.

10. Brucki SMD, Nitrini R, Caramelli P, Bertolucci PHF, Okamoto IH. [Suggestions for Mini Mental State Exam in Brazil]. Arq Neuropsiquiatr. 2003;61:777-81.

11. Chao HL, Tsai TY, Livneh H, Lee HC, Hsieh PC. Patients with colorectal cancer: relationship between demographic and disease characteristics and acceptance of disability. J Adv Nurs. 2010;66:2278-86.

12. Cheng C, Chan NY, Chio JH, Chan P, Chan AO, Hui WM. Being active or flexible? Role of control coping on quality of life among patients with gastrointestinal cancer. Psychooncology. 2012;21:211-8.

13. Cloninger CR. A systematic method for clinical description and classification of personality variants: a proposal. Arch Gen Psychiatry. 1987;44:573-88.

14. Costanzo ES, Sood AK, Lutgendorf SK. Biobehavioral influences on cancer progression. Immunol Allergy Clin North Am. 2011;31:109-32.

15. Engel J, Kerr J, Schlesinger-Raab A, Eckel R, Sauer H, Hölzel D. Quality of life in rectal cancer patients: a four-year prospective study. Ann Surg. 2003;238: 203-13.

16. Fearon K, Strasser F, Anker SD, Bosaeus I, Bruera E, Fainsinger RL, et al. Definition and classification of cancer cachexia: an international consensus. Lancet Oncol. 2011;12:489-95. 
17. Felder-Puig R, Formann AK, Mildner A, Bretschneider W, Bucher B, Windhager $\mathrm{R}$, et al. Quality of life and psychosocial adjustment of young patients after treatment of bone cancer. Cancer. 1998;83:69-75.

18. Finfgeld-Connett D. Clarification of social support. J Nurs Scholarsh. 2005;37:4-9.

19. Fleck MPA, Louzada S, Xavier M, Chachamovich E, Vieira G, Santos L, Pinzon V. [Application of the Portuguese version of the abbreviated instrument of quality life WHOQOL-bref]. Rev Saúde Pública. 2000;34:178-83.

20. Fuentes D, Tavares H, Camargo CHP, et al. In: Gorenstein C, Andrade LHSG, Zuardi AW. [Clinical Assessment Scales in Psychiatry and Psychopharmacology] São Paulo: Lemos Editorial; 2000. p. 363-76.

21. Gozzo TO, Panobianco MS, Clapis MJ, de Almeida, AM. [Dermatological Toxicity in Women With Breast Cancer Undergoing Chemotherapy Treatment] Rev Latinoam Enferm. 2010;18:681-7.

22. Graeff A, Leeuw JR, Ros WJ, Hordijk GJ, Blijham GH, Winnubst JA. Pretreatment factors predicting quality of life after treatment for head and neck cancer. Head Neck. 2000;22:398-407.

23. Julkunen J, Gustavsson-Lilius M, Hietanen P. Anger expression, partner support, and quality of life in cancer patients. J Psychosom Res. 2009;66:235-44.

24. Kune GA, Kune S, Watson LF, Bahnson CB. Personality as a risk factor in large bowel cancer: data from the Melbourne Colorectal Cancer Study. Psychol Med. 1991;21:29-41.

25. Moreira DF. [Pathological gambling: neuroimaging, neuropsychology and personality analyses] [dissertation]. São Paulo: Universidade de São Paulo; 2005. 143 p.

26. Muscaritoli M, Anker SD, Argilés J, Aversa Z, Bauer JM, Biolo G, et al. Consensus definition of sarcopenia, cachexia and pre-cachexia: joint document elaborated by Special Interest Groups (SIG) "cachexia anorexia in chronic wasting diseases" and "nutrition in geriatrics". Clin Nutr. 2010;29:154-9.

27. Myers DG, Diener E. Who is happy? Psychol Sci. 1995;6:10-9.

28. Pedro ICS, Rocha SMM, Nascimento LC. [Social support and social network in family nursing: reviewing concepts]. Rev Latinoam Enferm. 2008;16:324-7.

29. Pinto RN, Chaves AC, Lourenço MT, Mari J de J. Information needs of needs of recently diagnosed cancer patients in Brazil. Information needs of recently diagnosed cancer patients in Brazil. Int J Psychiatry Med. 2004;34:319-29.
30. Rodrigues JSM, Ferreira NMLA. [Structure and functionality of the social support network for adults with cancer]. Acta Paul Enferm. 2012;25:781-7.

31. Scharloo M, Baatenburg de Jong RJ, Langeveld TP, van Velzen-Verkaik E, Doornop den Akker MM, Kaptein AA. Quality of life and illness perceptions in patients with recently diagnosed head and neck cancer. Head Neck. 2005;27:857-63.

32. Shun SC, Hsiao FH, Lai YH, Liang JT, Yeh KH, Huang J. Personality trait and quality of life in colorectal cancer survivors. Oncol Nurs Forum. 2011;38:E221-8.

33. Sun DZ, Liu L, Jiao JP, Wei PK, Jiang LD, Xu L. Syndrome characteristics of traditional Chinese medicine: summary of a clinical survey in 767 patients with gastric cancer. Zhong Xi Yi Jie He Xue Bao. 2010;8:332-40.

34. Svedlund J, Sullivan M, Liedman B, Lundell L. Relationship of tumor burden and patients' minimization of distress in facing surgery for gastric cancer. Psychosomatics. 2005;46:233-43.

35. Thomas SP, Groer M, Davis M, Droppleman P, Mozingo J, Pierce M. Anger and cancer: an analysis of the linkages. Cancer Nurs. 2000;23:344-9.

36. Visentin A, Labronici L, Lenardt MH. Autonomia do paciente idoso com câncer: o direito de saber o diagnóstico. Acta Paul Enferm. 2007;20:509-13.

37. White VM, English DR, Coates H, Lagerlund M, Borland R, Giles GG. Is cancer risk associated with anger control and negative affect? Findings from a prospective cohort study. Psychosom Med. 2007;69:667-74.

38. World Health Organization. Cancer [Internet]. Geneva: WHO; 2016. [cited 2016 Jan 25]. Available from: http://www.who.int/cancer/en/

39. World Health Organization. Cancer [Internet]. Geneva: WHO; 2015. [cited 2016 Jan 25]. Available from: http://www.who.int/mediacentre/factsheets/fs297/en/

40. Yamaoka K, Shigehisa T, Ogoshi K, Haruyama K, Watanabe M, Hayashi F, Hayashi C. Health-related quality of life varies with personality types: a comparison among cancer patients, non-cancer patients and healthy individuals in a Japanese population. Qual Life Res. 1998;7:535-44.

41. Yan H, Sellick K. Quality of life of Chinese patients newly diagnosed with gastrointestinal cancer: a longitudinal study. Int J Nurs Stud. 2004;41:309-19.

42. Zhou FL, Zhang WG, Wei YC, Xu KL, Hui LY, Wang XS, Li MZ. Impact of comorbid anxiety and depression on quality of life and cellular immunity changes in patients with digestive tract cancers. World J Gastroenterol. 2005;11:2313-8. 